\title{
Pharmaceutical Equivalence of Hydrochlorothiazide Tablets in Argentina
}

María A. Varillas ${ }^{1}$, Marta I.V. Brevedan ${ }^{1}$, and Noelia L. Gonzalez Vidal,2*

${ }^{1}$ Medicine Quality Control, Department of Biology, Biochemistry and Pharmacy, Universidad Nacional del Sur, Bahía Blanca, Argentina ${ }^{2}$ CONICET-UNS, Bahía Blanca, Argentina

\section{ABSTRACT}

Hydrochlorothiazide (HCTZ) is a diuretic used to treat hypertension, which belongs to Class III of the Biopharmaceutics Classification System. The present study aimed to evaluate critical quality parameters of HCTZ solid oral dosage forms on the Argentine pharmaceutical market. For this purpose, evaluation of labels and patient information leaflets, description and mean weight of tablets, uniformity of dosage units, assay, hardness, friability, disintegration and dissolution tests were carried out, in compliance with the Argentine Pharmacopeia. The dissolution efficiency (DE) was obtained from the area under the drug dissolution curve, and the profiles were compared statistically by ANOVA. All samples met criteria for the assay, uniformity of dosage units, friability, hardness, disintegration tests, and dissolution test in Stage 1. Sample D presented the lowest dissolution performance, in terms of DE values, with highly significant differences in comparison with the rest of the evaluated samples; however, the results of this study indicate that HCTZ tablets available in Argentina successfully pass all established quality control tests and can be considered pharmaceutical equivalents.

KEYWORDS: Dissolution, hydrochlorothiazide, pharmaceutical equivalence, dissolution efficiency

\section{INTRODUCTION}

ydrochlorothiazide (HCTZ) is a thiazide diuretic that blocks the specific sodium transport in the nephron; it is mainly used for the treatment of edema, arterial hypertension, congestive heart failure, and several forms of renal and hepatic dysfunctions (1). It is administered orally, at doses of 25 and $50 \mathrm{mg}$ in tablet form (2).

There is not agreement in the classification criterion of HCTZ, according to the Biopharmaceutical Classification System (BCS) (3). Some authors consider it as a Class IV or II drug $(4,5)$. However, most authors classify HCTZ as a Class III drug (i.e., high solubility and low permeability) $(3,6-8)$.

In Argentina, HCTZ tablets are available both as reference and multisource products; however, it is a common practice that patients replace not only the reference with multisource products, but also replace multisource products with the latest ones. It is important to point out that multisource products must have proven pharmaceutical equivalence with the reference.

To establish that products containing the same amount of active pharmaceutical ingredient (API) (in the same pharmaceutical form and designed to be administered by the same route) are pharmaceutical equivalents, it must be verified that all of them comply with quality standards, such as identity, potency, dose uniformity, dissolution test and profile, and information regarding storage conditions $(9,10)$.

In vitro dissolution testing is an economic and useful tool to assure product quality, and to estimate pharmaceutical equivalence to the reference product (11). The point estimate approach is suitable for products containing APIs with high solubility-high permeability, but it may not be adequate for low solubility or low permeability ones. In these situations, products with inherently different dissolution profiles may sometimes comply with the point estimate given as a pharmacopeia standard. This, in turn, may inadvertently lead to the declaration of similar dissolutions. Dissolution profile comparison seems to be more precise than the point estimate approach for accurate characterization of the drug product $(12,13)$.

This study aimed to evaluate the quality and pharmaceutical equivalence of commercial products containing HCTZ (50 mg) marketed in Argentina, based on local Pharmacopeia guidelines.

*Corresponding author 


\section{METHODS AND MATERIALS}

\section{Chemicals and Reagents}

HCTZ was purchased from Saporiti (Parafarm, Argentina). Analytical grade sodium hydroxide and hydrochloric acid were used in the assay, uniformity of dosage units and dissolution tests (Anedra, Argentina).

\section{Tablet Samples}

Four different HCTZ $(50 \mathrm{mg}$ ) tablets were purchased at pharmacies in Bahia Blanca, Argentina. Tablets were randomly labeled as $A$ to $D$. Reference product was Sample B; and A, C and D were multisource products.

\section{Equipment}

A Varian Cary 50 Conc spectrophotometer (Varian Instruments, Australia) was used for assay and dissolution studies. Hardness of the tablets was measured using a Scout DGM02 hardness tester (Scout Electronics, Argentina), friability via a Scout FGMO2, and disintegration with a Scout EGMO2. Dissolution studies were performed with an Erweka DT60 (Erweka GmbH, Germany). An Acculab ALC-210.4M electronic analytical balance (Acculab, USA) was used to weigh materials/ chemicals and tablets.

\section{Quality Control Tests}

A comparative study of the information present on labels of primary and secondary packaging and in patient leaflets of the different samples was carried out to verify compliance with local legislation $(14,15)$.

For weight variation analysis, 10 tablets from each commercial sample were randomly chosen and individually weighed using an analytical balance. The mean weight and standard deviation (SD) were calculated.

Friability, hardness, and disintegration tests were performed according to the Argentine Pharmacopeia (14). A friability test determines the ability of tablets to withstand abrasion during packaging, handling, and shipping processes. Ten tablets from each commercial sample were weighed separately, placed into the friability tester and rotated at $25 \mathrm{rpm}$ for $4 \mathrm{~min}$ (100 revolutions). Then, the tablets were removed from the tester and weighed, comparing this result with the initial value. The weight loss due to abrasion was expressed as a percentage. A maximum weight loss of not more than $1 \%$ is considered acceptable (14). The hardness of 10 individual tablets of each sample was measured using a hardness tester, where the tablets were placed between two platens, one of which moved to apply sufficient force to the tablet to cause fracture. This tester measures the degree of force in kilopounds $(\mathrm{kp})$ required to break a tablet across the diameter. Lastly, the disintegration time of tablets $(n=6)$ was determined in water at $37.0 \pm 2.0^{\circ} \mathrm{C}$ using a disintegration tester. After 30 minutes, it should be observed that all tablets completely disintegrate, unless otherwise specified in the corresponding monograph (14).

For HCTZ assay tests, 20 tablets were weighed and powdered. Then, an accurately weighed portion of the powder, equivalent to about $30 \mathrm{mg}$ of HCTZ, was dissolved using $0.1 \mathrm{M}$ sodium hydroxide and diluted to volume. The solution was filtered and diluted with water. Drug concentration was determined by UVspectrophotometry $(272 \mathrm{~nm}$ ) (16). The HCTZ content was calculated using a standard calibration curve $(y=0.0530$ $\left.\mathrm{x}-0.0133 ; R^{2}=0.9998\right)$ developed for this purpose.

For uniformity of dosage units test, 10 tablets of each commercial sample were individually evaluated according to the assay method.

Dissolution profiles were performed as recommended in the Argentine Pharmacopeia for dissolution quality control test, using sampling points of $5,10,15,30$, 45, 60 , and 75 minutes (14). Apparatus 1 (basket) at $100 \mathrm{rpm}$ was used, with $900 \mathrm{~mL}$ of $0.1 \mathrm{M}$ hydrochloric acid $(\mathrm{HCl})$ as dissolution medium. At the specified times, $10-\mathrm{mL}$ aliquots were taken, filtered through a $0.45-\mu \mathrm{m}$ nylon membrane filter (Microclar, Argentina) and suitably diluted. The amount of HCTZ dissolved was calculated by comparing the measured absorbance at $272 \mathrm{~nm}$ with the calibration curve prepared for that purpose. A standard calibration curve of HCTZ concentration $(\mu \mathrm{g} / \mathrm{mL})$ versus absorbance was represented by the linear equation $y=0.0655 x-0.0005$, with a correlation coefficient of 0.9998 (concentration range $2.0-12.0 \mu \mathrm{g} / \mathrm{mL}$ ). The Argentine Pharmacopeia indicates that not less than $60 \%(Q)$ of the labeled amount of HCTZ should dissolve within $60 \mathrm{~min}$ (14). In addition, dissolution profiles were statistically evaluated, in terms of dissolution efficiency (DE), using analysis of variance (ANOVA, Infostat). DE was calculated as the ratio, in percentage, of the area under the curve obtained from the dissolution profile, with the total area of the rectangle considered as $100 \%$ dissolution for the same time interval (17).

\section{RESULTS AND DISCUSSION}

A comparative study of the information presented on labels (primary and secondary packaging) and patient leaflets of all products was performed based on World Health Organization (WHO) advice and local regulations $(10,14,15)$. The concept of interchangeability is applicable not only to the API and to the pharmaceutical 
form, but also to the instructions for use and storage specifications, especially when they are critical for stability and expiration date. Concerning packaging and storage conditions, the Argentine Pharmacopeia states to "preserve in well-closed containers" (14). The labels and leaflets of the tested samples revealed differences in storage recommendations (Table 1). Formulation A labels indicated to "store in its original packaging", whereas the other samples did not mention this factor. In addition, the label information did not match the one described in the leaflet. Products $A, B$, and D referred to a maximum storage temperature. It is important to point out that information included in labels and leaflets should be uniform across producers and controlled by regulatory agencies, so both patients and professionals can interpret them correctly.

In Argentina, the widespread use of multisource products and interchangeability decisions taken by patients are generally based on economic reasons. Multisource HCTZ products exhibited similar price values, whereas the reference product was almost $40 \%$ higher (Table 1 ). This situation could lead to a misunderstanding about product quality.

The results of physical quality control tests, performed as recommended by the Argentine Pharmacopeia, are shown in Table 1. The evaluation of weight values identified large differences between samples, with results ranging from 149.4 to $250.6 \mathrm{mg}$. Differences in composition, typical of each manufacturer, and the physical dimensions of each product can explain this range of results, without necessarily being related to variations in the API content or dissolution performance.

Another measure of the mechanical integrity of tablets is their breaking force, which is the force required to cause them to fail (i.e., break) in a specific plane, called hardness in the pharmaceutical literature. It is expected that no tablet have hardness results lower than $2.0 \mathrm{kp}$. The tablets were tested individually, and mean hardness values ranged between 3.5 and $10.7 \mathrm{kp}$ for all tested products (Table 1 ). The friability test indicated very low loss of powder $(<0.5 \%)$, which complied with the maximum allowed value of $1 \%$ (14) (Table 1). The tested products also showed satisfactory disintegration results, between 28 and 360 s. (Table 1). Therefore, all samples met the official compendium requirement of $30 \mathrm{~min}$ disintegration (14).

The HCTZ assay, uniformity of dosage units, and dissolution results are shown in Table 2. Assay results ranged from $93.6 \% \pm 2.5 \%$ (Sample B) to $99.6 \% \pm 1.4 \%$ (Sample A), and dissolution results were higher than $95 \%$ of labeled amount dissolved in 60 minutes for all samples, except for Sample D (values higher than 70\%). Therefore,

Table 1. Information of Evaluated Products and Results of Physical Quality Control Tests

\begin{tabular}{|c|c|c|c|c|c|c|}
\hline Sample & Price $^{a}$ & Storage conditions & $\begin{array}{l}\text { Tablet weight } \\
(\mathrm{mg})^{\mathrm{b}}\end{array}$ & $\begin{array}{l}\text { Hardness } \\
(\mathbf{k p})^{\mathrm{b}}\end{array}$ & $\begin{array}{l}\text { Friability (\% of } \\
\text { weight loss) }\end{array}$ & $\begin{array}{c}\text { Disintegration } \\
\text { Time }(\mathrm{s})^{c}\end{array}$ \\
\hline A & 27.1 & $\begin{array}{l}\text { B: Store in original packaging at room temperature, not } \\
\text { greater than } 30^{\circ} \mathrm{C} . \\
\text { L: Store below } 30^{\circ} \mathrm{C} .\end{array}$ & $149.4 \pm 2.8$ & $3.5 \pm 0.2$ & 0.41 & 360 \\
\hline B (ref) & 35.9 & $\mathrm{~B}$ and $\mathrm{L}$ : Store away from heat (not more than $30^{\circ} \mathrm{C}$ ). & $199.5 \pm 2.7$ & $10.7 \pm 0.8$ & 0.17 & 210 \\
\hline C & 22.0 & B and L: Store in cool and dry room. & $250.6 \pm 2.4$ & $5.5 \pm 0.4$ & 0.04 & 28 \\
\hline D & 25.0 & $\mathrm{~B}$ and $\mathrm{L}$ : Store at a temperature below $30^{\circ} \mathrm{C}$. & $161.1 \pm 2.4$ & $6.1 \pm 0.3$ & 0.31 & 95 \\
\hline
\end{tabular}

${ }^{a}$ Price in Argentine pesos at the time of analysis for 10 tablets; ${ }^{b}$ Mean value \pm standard deviation; ${ }^{c}$ Maximum time needed for complete disintegration of evaluated tablets; B, labels; L, leaflets; $k p$, kilopound.

Table 2. Assay, Uniformity of Dosage Units, and Dissolution Test Results

\begin{tabular}{|c|c|c|c|c|}
\hline & Assay (\%) & $\begin{array}{c}\text { Uniformity of Dosage } \\
\text { Units }\end{array}$ & $\begin{array}{c}\text { Dissolution Test } \\
\text { (S1 Stage) }^{\mathbf{c}}\end{array}$ & $\begin{array}{c}\text { Dissolution } \\
\text { Efficiency (\%) }\end{array}$ \\
\hline Sample Specification & $90.0-110.0$ & $\begin{array}{c}85.0-115.0 ; \\
\mathrm{RSD}<6.0\end{array}$ & $60 \%(Q)$ in $60 \mathrm{~min}$. & \\
\hline A & $99.6 \pm 1.4$ & {$[97.6-100.9] / 1.4$} & {$[97-105] / 2.7$} & $86.8 \pm 1.8$ \\
\hline B (ref) & $93.6 \pm 2.5$ & {$[90.2-97.0] / 2.7$} & {$[97-99] / 0.8$} & $93.0 \pm 0.4$ \\
\hline C & $98.6 \pm 4.1$ & {$[93.8-103.5] / 4.2$} & {$[101-105] / 1.6$} & $90.8 \pm 1.1$ \\
\hline D & $94.5 \pm 1.9$ & {$[92.3-96.5] / 2.0$} & {$[71-79] / 4.5$} & $66.5 \pm 2.8$ \\
\hline
\end{tabular}

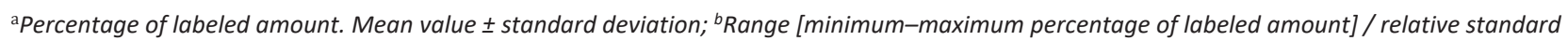
deviation (RSD); ${ }^{C}$ Range [minimum-maximum percentage of labeled amount dissolved] / RSD. 
all formulations complied with the specifications of the Argentine Pharmacopeia for HCTZ content, uniformity of dosage units, and Stage 1 dissolution tests (14).

Figure 1 shows the dissolution profiles of HCTZ tablets in $0.1 \mathrm{M} \mathrm{HCl}$, presented as mean percentages of labeled amount, associated with its corresponding standard deviation value. Dissolution profile analysis is an important tool to evaluate formulation development and marketed products, for batch quality control and establishing similarity between multisource and reference formulations. After $30 \mathrm{~min}$, the dissolution profiles of the reference product $B$ and multisource products $A$ and $C$ practically superimposed, indicating similar drug dissolution until the end of the test (Fig. 1). Samples $B$ and $C$ could be considered as 'very rapid dissolution' products, while Sample A revealed a 'rapid dissolution' performance (18). On the other hand, Sample D presented a significantly lower dissolution performance throughout the whole profile, with less than $85 \%$ dissolved (Fig. 1).

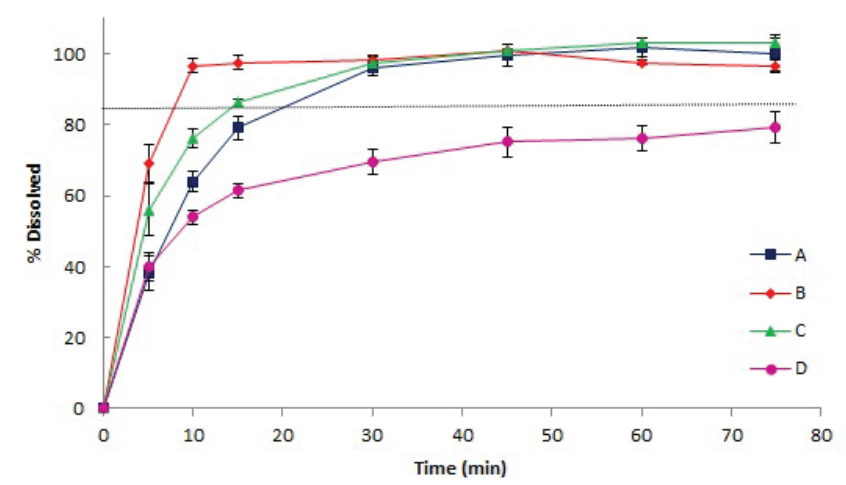

Figure 1. Hydrochlorothiazide dissolution profile in $0.1 \mathrm{M} \mathrm{HCl}$. Each line represents the mean percentage of labeled amount dissolved, associated with its corresponding standard deviation, for samples $A-D(B$, ref). Dotted line represents $85 \%$ dissolved level.

DE was also used to assess HCTZ release and dissolution profile comparison. If a drug has a high $\mathrm{DE}$, it can be inferred that the API remains in contact with physiologic membranes for a long time and, thus, could lead to greater bioavailability in the assessed concentration range. $D E$ results were above $85 \%$ for Samples A-C, whereas Sample $D$ exhibited the lowest values (Table 2). ANOVA revealed statistical differences between Sample $D$ and the other products $(p<0.01)$. Moreover, no statistical differences were recorded between the reference product $B$ and Sample C $(p<0.01)$.

Several factors may influence dissolution results, such as the disintegration rate and the nature of the excipients. The use of excipients in HCTZ tablet composition is warranted due to being an immediate-release solid oral dosage form, ready to release the drug rapidly after administration. In these formulations, soluble diluents, disintegrating agents, and/or other resources are employed to promote disintegration, release, and dissolution $(19,20)$. By analyzing the excipients composition of the evaluated formulations, some observations can be made (Table 3). The reference formulation $B$ contained lactose as diluent and two disintegrants. The two multisource formulations that achieved an appropriate release profile, products $A$ and $C$, were very different in composition (Table 3, Fig. 1). Product A showed four disintegrants, associated with the soluble diluent lactose, which may be responsible for the adequate dissolution. Product $\mathrm{C}$ contained a single disintegrant associated with two diluents, lactose and cellulose. A previous study recommended avoiding formulations containing lactose and mannitol, because they are incompatible with HCTZ (21); however, our results are not in agreement with this observation because the formulations with better dissolution profiles ( $A, B$ and $C$ ) contained lactose, whereas product $D$ had the lowest dissolution performance though it did not have this diluent. On the other hand, product $D$ contained two disintegrants (povidone and croscarmellose), associated with a surfactant (sodium lauryl sulfate) and a diluent, such as microcrystalline cellulose (Table 3 ). These were all excipients that promote disintegration and dissolution. However, the dissolution profile of product D was not appropriate (Fig. 1). This could be related to the presence of the water-insoluble colorant (aluminum lake) or the method of manufacture (information not provided by the producer nor found in the literature).

Table 3. Qualitative Composition of Excipients

\begin{tabular}{|c|c|c|c|c|c|}
\hline Excipient type & Excipient $\quad$ Sample & A & $B($ ref) & C & D \\
\hline \multirow{2}{*}{ Filler / Diluent } & Lactose & + & + & + & - \\
\hline & Cellulose, microcrystalline ${ }^{a}$ & - & - & + & + \\
\hline \multirow{5}{*}{ Disintegrant } & Corn starch ${ }^{\mathrm{a}}$ & + & + & - & - \\
\hline & Povidone $^{a}$ & + & + & - & + \\
\hline & Crospovidone & + & - & - & - \\
\hline & Croscarmellose sodium & + & - & - & + \\
\hline & Sodium starch glycolate & - & - & + & - \\
\hline \multirow{2}{*}{ Glidant } & Sodium lauryl sulphate ${ }^{a}$ & - & - & - & + \\
\hline & Colloidal silicon dioxide & - & - & + & + \\
\hline Lubricant & Magnesium stearate & + & + & + & + \\
\hline Colorant & Aluminum lake & - & - & - & + \\
\hline
\end{tabular}

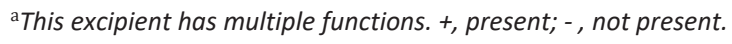




\section{CONCLUSION}

Multisource HCTZ tablets available in Argentina, together with the reference product, were subjected to analysis according to the Argentine Pharmacopeia. The results have shown that all the tested samples fulfilled the local requirements in terms of HCTZ content, friability, disintegration, uniformity of dosage units, and dissolution tests. Although one multisource product (Sample D) exhibited a lower dissolution performance, based on a reduced dissolution profile and DE results, it could be concluded that all evaluated products are pharmaceutical equivalents according to the Argentine Pharmacopeia. Further evaluation in relevant dissolution media will be performed to assess similarity and interchangeability of these formulations and their pharmaceutical stability.

\section{ACKNOWLEDGEMENTS}

The authors thank Universidad Nacional del Sur for financial support of this study (PGI 24/ZB70).

\section{CONFLICT OF INTEREST}

The authors disclosed no conflicts of interest related to this article.

\section{REFERENCES}

1. Ives, H. E. Agentes Diuréticos. In Farmacologia Básica y Clínica, 11th ed.; Katzung, B. G.; Masters, S. B.; Trevor, A. J., Eds.; McGraw-Hill Interamericana: Mexico, 2010; pp. 251-276.

2. Jackson, E. K. Diuréticos. In Las Bases Farmacológicas de la Terapéutica, 10th ed.; Goodman, L. S.; Gilman, A. G, Eds.; McGraw-Hill Interamericana: Mexico, 2001; pp. 767-798.

3. Amidon, G. L.; Lennernas, H.; Shah, V. P.; Crison, J. R. A theoretical basis for a biopharmaceutical drug classification: the correlation of in vitro drug product dissolution and in vivo bioavailability. Pharm. Res. 1995, 12, 413-420. DOI: 10.1023/A: 1016212804288.

4. Löbenberg, R.; Amidon, G. A. Modern bioavailability, bioequivalence and biopharmaceutics classification system. New scientific approaches to international regulatory standard. Eur. J. Pharm. Biopharm. 2000, 50, 3-12. DOI: 10.1016/S09396411(00)00091-6.

5. Khan, A.; Iqbal, Z.; Shah, Y.; Ismail, L.; Ullah, Z.; Ullah, A. Enhancement of dissolution rate of class II drugs (Hydrochlorothiazide); a comparative study of the two novel approaches; solid dispersion and liqui-solid techniques. Saudi Pharm. J. 2015, 23, 650-657. DOI: 10.1016/j.jsps.2015.01.025.

6. Kasim, N. A.; Whitehouse, M.; Ramachandran, C.; Bermejo, M.; Lennernas, H.; Hussain, A. S.; Junginger, H. E.; Stavchansky, S. A.; Midha, K. K.; Shah, V.P.; Amidon, G. L. Molecular properties of WHO essential drugs and provisional biopharmaceutical classification. Mol. Pharm. 2003, 1, 85-96. DOI: 10.1021/ mp034006h.

7. Ono, A.; Sugano, K. Application of the BCS biowaiver approach to assessing bioequivalence of orally disintegrating tablets with immediate release formulations. Eur. J. Pharm. Biopharm. 2014, 64, 37-43. DOI: 10.1016/j.ejps.2014.08.003.

8. Lindenberg, M.; Kopp, S.; Dressman, J. Classification of orally administered drugs on the World Health Organization Model list of Essential Medicines according to the biopharmaceutics classification system. Eur. J. Pharm. Biopharm. 2004, 58, 265278. DOI: 10.1016/j.ejpb.2004.03.001.

9. ANMAT 3185 Regulation: Approval of the technical recommendations contained in the document "Schedule for requirements of equivalence studies between medicines of significant health risk"; Administración Nacional de Medicamentos, Alimentos y Tecnología Médica (ANMAT): Buenos Aires, Argentina, 1999. Accessed February 20, 2018.http://www.anmat.gov.ar/webanmat/Legislacion/ Medicamentos/Disposicion_ANMAT_3185-1999.pdf

10. Multisource (generic) pharmaceutical products: guidelines on registration requirements to establish interchangeability. In: WHO Expert Committee on Specifications for Pharmaceutical Preparations: 51st Report. World Health Organization: Geneva, Switzerland; 2017: Annex 6 (WHO Technical Report Series, No. 1003); pp 181-236.

11. Dressman, J.; Kramer, J. Pharmaceutical Dissolution Testing. Marcel Dekker: New York; 2005.

12. Sathe, P. M.; Tsong, Y.; Shah, V. P. In vitro dissolution profile comparison: statistics and analysis, model dependent approach. Pharm. Res. 1996, 13, 1799-1803. DOI: 10.1023/A:1016020822093.

13. Shah, V. P.; Tsong, Y.; Sathe, P.; Williams, R. L. Dissolution profile comparison using similarity factor, $f^{2}$. Dissolution Technol. 1999, 6, 15. DOI: 10.14227/DT060399P15.

14. Farmacopea Argentina, 7th ed.; Administración Nacional de Medicamentos, Alimentos y Tecnología Médica (ANMAT): Buenos Aires, Argentina, 2013.

15. ANMAT 5904 Regulation: Definitions and general guidelines on how information should be included in the leaflets of medicinal products, whose condition of sale is under prescription in its three categories; Administración Nacional de Medicamentos, Alimentos y Tecnología Médica (ANMAT): Buenos Aires, Argentina, 1996. Accessed February 20, 2018. http:// www.anmat.gov.ar/webanmat/NORMATIVA/NORMATIVA/ MEDICAMENTOS/DISPOSICION_ANMAT_5904-1996.PDF.

16. The British Pharmacopoeia, Vol. III; The Stationary Office: London, 2009.

17. Khan, K. A. The concept of dissolution efficiency. J. Pharm. Pharmacol. 1975, 27, 48-49. DOI: 10.1111/j.2042-7158.1975. tb09378.x. 
18. Waiver of In Vivo Bioavailability and Bioequivalence Studies for Immediate-Release Solid Oral Dosage Forms Based on a Biopharmaceutics Classification System; Guidance for Industry; U.S. Department of Health and Human Services, Food and Drug Administration, Center for Drug Evaluation and Research (CDER), U.S. Government Printing Office: Washington, DC, 2015.

19. Alderborn, G. Comprimidos y Compactación. In La Ciencia del
Diseño de las Formas Farmacéuticas, 2nd Ed.; Aulton, M. E., Ed.; Elsevier: España; 2004, pp 397-440.

20. Costa, P.; Sousa Lobo J. M. Modeling and comparison of dissolution profiles. Eur. J. Pharm. Sci. 2001 13, 123-133. DOI: 10.1016/S0928-0987(01)00095-1.

21. De Oliveira, M.; Yoshida, M.; Gonçalves Monteiro da Silva, D. Quality evaluation of pharmaceutical formulations containing
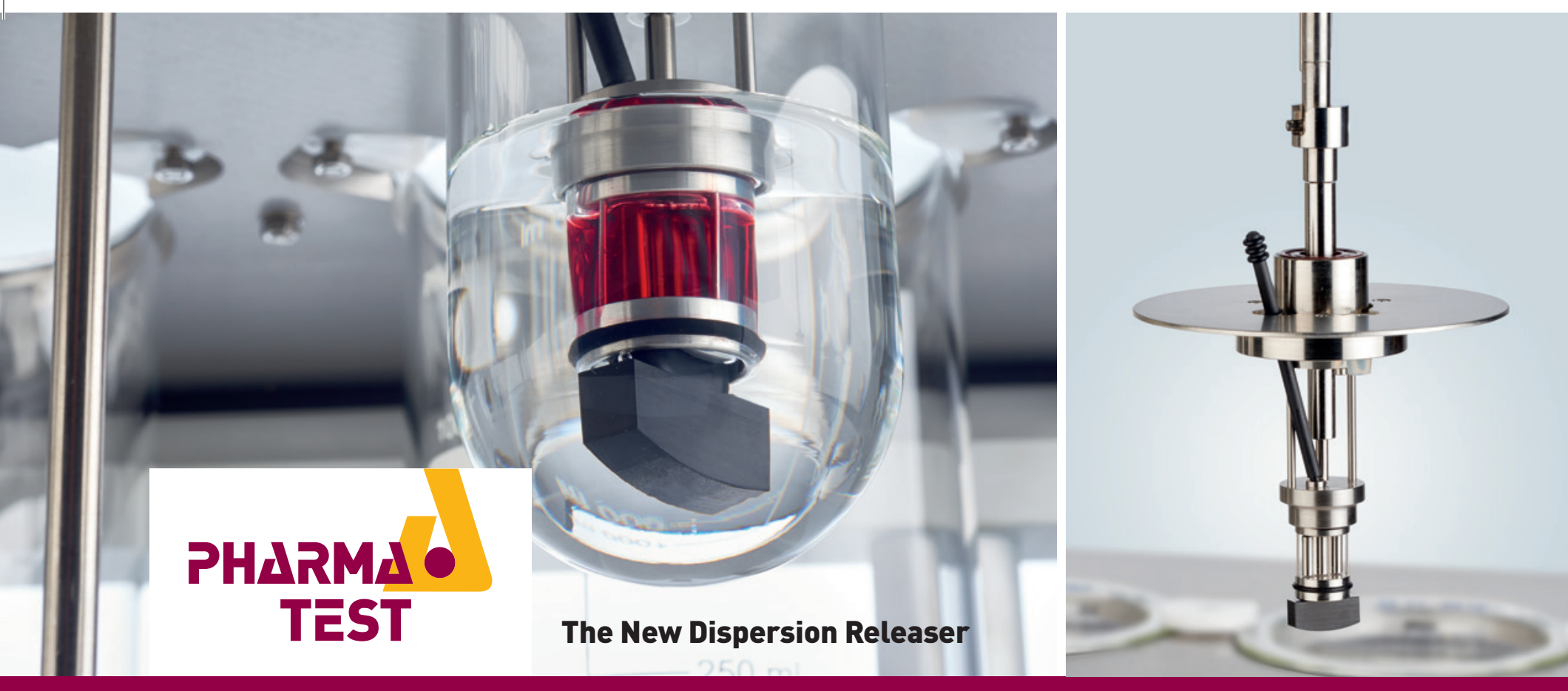

One of the most effective and reproducible way to test nanomedicines, microformulations and semi-solid dosage forms. It's „The German Gründlichkeit“.

www.pharma-test.com
The Dispersion Releaser PT-DR is a new dissolution apparatus to test the release of nanomedicines, microformulations and semi-solid dosage forms. It has been shown to be the most effective and reproducible way to test products with very low up to high solubility. The system consists of a donor and acceptor chamber which is surrounded by a membrane. Both chambers are agitated. This specific design allows controlling the shear forces applied to the nanoformulation. The PT-DR is compatible with all Pharma Test PTWS dissolution testers and also with each standard USP dissolution tester. 